\title{
Antibody isotypes to a Paracoccidioides brasiliensis somatic antigen in sub-acute and chronic form paracoccidioidomycosis
}

\author{
MiCHELANGELO JuVENALE, GILDA M. B. DEL NEGRO, ALBERTO J. S. DUARTE and GIL \\ BENARD
}

Laboratório de Alergia e Imunologia Clínica e Experimental, Faculdade de Medicina da Universidade de São Paulo and Laboratório de Micologia Médica, Instituto de Medicina Tropical de São Paulo, Brazil

\begin{abstract}
This report describes the differences in isotype antibody reactivity against a crude Paracocidioides brasiliensis antigenic preparation in the sub-acute (SAF) and chronic (CF) forms of paracoccidioidomycosis before treatment. IgG antibodies were detected in all patients, with a slightly but not significantly higher reactivity in the SAF. IgG1 antibodies were present, frequently at high levels, in both forms, whereas IgG3 was always low or absent. IgG2 antibodies were detectable in most patients, but at high levels in only a few CF patients. IgG4 was found mainly in SAF patients, whereas IgA was detected almost only in CF patients, probably due to a Th2 pattern of immune response in the more severe $\mathrm{SAF}$, and the characteristic mucosal involvement of the $\mathrm{CF}$, respectively. Immunoblot analysis showed that, in addition to the 43-kDa immunodominant fraction, other less well-characterised fractions were also recognised differentially by the isotypes and deserve further investigation.
\end{abstract}

\section{Introduction}

Paracoccidioidomycosis (PCM) is one of the most important endemic deep mycoses in Latin America [1]. It is a chronic granulomatous disease caused by the dimorphic fungus Paracoccidioides brasiliensis and has an important social and economic impact, for it affects healthy men during their productive years, causing respiratory tract mucosal or cutaneous lesions, or both [1]. The infection is acquired by inhalation of conidiospores present in the soil, but its reservoir is still not fully characterised [2]. The mucosal lesions can vary from isolated oral ulceration to diffuse interstitial pulmonary involvement. However, most patients present multiple lesions at different sites of the respiratory tract. This form of the disease, called the chronic form (CF), mainly affects adult men and may develop many years after the patients have left the endemic area. In contrast, the less frequently observed sub-acute form (SAF) affects both sexes, mainly under 30 years of age, and probably develops soon after exposure to the fungus. Patients with the SAF present

Received 25 Jan. 2000; revised version received 27 April 2000; accepted 19 May 2000.

Corresponding author: Dr G. Benard (e-mail: mahong@, usp.br). with visceral involvement, predominantly of the mononuclear-phagocytic system [1].

PCM has been associated with variable degrees of depression of the cellular immune response and enhancement of the humoral immune response. The latter has been characterised by B-cell polyclonal activation, hypergammaglobulinaemia, and high serum levels of anti- $P$. brasiliensis antibodies [3-5]. Evaluation of the humoral immune response has been an important tool for diagnosis and follow-up of PCM patients. The level of specific antibody production has been used as a correlate of disease severity as well as for assessment of treatment response [1]. Various techniques and antigenic preparations have been described in the literature to assess anti- $P$. brasiliensis antibody response [6]. This laboratory has been using a counterimmuno-electrophoresis (CIE) test [7], and more recently, an enzyme-linked immunosorbent assay (ELISA) [8] successfully. The ELISA was introduced because it allows the processing of greater numbers of samples and uses a crude preparation in which at least 18 antigenic fractions are present [8], thus being more representative of the whole fungus, whereas the CIE employs a culture filtrate antigen whose major component is the $43-\mathrm{kDa}$ fraction [6].

The present study aimed to characterise the reactivity 
of total IgG, its subclasses, and IgA against the crude P. brasiliensis preparation by ELISA and immunoblotting.

\section{Materials and methods}

\section{Patients and control sera}

Sera from 47 untreated PCM patients were used. Sera were generally collected before treatment, as part of the diagnosis of PCM. Sera were divided and frozen in small volumes at $-20^{\circ} \mathrm{C}$ until use. Patients were classified as SAF $(n=14)$ or $\operatorname{CF}(n=33)$ according to the clinical presentation of the disease [1]. Sera from 40 healthy blood donors were also used to determine cut-off values of the ELISA.

\section{Double immunodiffusion and counterimmuno- electrophoresis tests}

A culture filtrate from a 10-day culture of the yeast phase of $P$. brasiliensis strain 113 (Culture Collection, Instituto de Medicina Tropical de São Paulo) was used for these assays, as described previously $[7,8]$. The double immunodiffusion test (DID) was performed in agar $1 \%$ gel in buffered saline $(\mathrm{pH}$ 6.9) containing sodium citrate $0.4 \%$ and glycine $7.5 \%$ and the serum samples were tested undiluted, as described previously $[7,8]$. Counterimmuno-electrophoresis (CIE) was performed in agarose $1 \%$ gel with electrophoresis in veronal-buffered saline, $\mathrm{pH} 8.2$, at $120 \mathrm{~V}$ for $90 \mathrm{~min}$. Serum samples were applied in the anodic side, and the antigen in the cathodic side of the slide. The sera were diluted in a two-fold series and tested from the undiluted sample. Samples that reacted at least undiluted were considered positive [7].

\section{P. brasiliensis somatic antigen}

A cellular yeast extract (somatic antigen) prepared as described previously [8] was used for the ELISA. Briefly, P. brasiliensis yeast cells (strains 113 and 339, the latter kindly supplied by A. Restrepo, CIB, Medellin, Colombia) were cultivated in Fava Netto's agar medium at $36^{\circ} \mathrm{C}$ for 7 days. Then, the cells were resuspended in $0.01 \mathrm{M}$ phosphate-buffered saline (PBS, $\mathrm{pH}$ 7.2) containing $10 \mathrm{~mm}$ phenylmethylsulphonylfluoride as protease inhibitor. Cells were ruptured by maceration in the presence of glass beads and liquid nitrogen. After centrifugation at $10000 \mathrm{rpm}$ for $15 \mathrm{~min}$, the supernate was filtered by sterilising membranes, divided into small volumes and stored at $-20^{\circ} \mathrm{C}$. The protein content was $1.97 \mathrm{mg} / \mathrm{ml}$ as determined by Lowry's method [9].

\section{ELISA for IgG, IgG subclasses and IgA anti- $P$. brasiliensis somatic antigen}

ELISA for IgG anti-P. brasiliensis somatic antigen was done as described previously [10], with a few modifications [8]. Briefly, polystyrene high-binding microplates (Costar, Cambridge, MA, USA) were coated with $P$. brasiliensis somatic antigen $(25 \mu \mathrm{g} / \mathrm{ml})$ diluted in $0.1 \mathrm{M}$ carbonate-bicarbonate buffer $(\mathrm{pH}$ 9.6) and incubated at $37^{\circ} \mathrm{C}$ for $1 \mathrm{~h}$ and at $4{ }^{\circ} \mathrm{C}$ overnight. Plates were washed with PBS and blocked with PBSgelatin $0.05 \%$-BSA $2 \%$ for $1 \mathrm{~h}$ at $37^{\circ} \mathrm{C}$. After washing the plates with PBS-Tween $0.1 \%, 50 \mu \mathrm{l}$ of the dilutions of the patients' sera were added and incubated for $2 \mathrm{~h}$ at $37^{\circ} \mathrm{C}$. Plates were washed and an anti-human $\gamma$-chain biotinylated monoclonal antibody (MAb) (Sigma) diluted 1 in 800 in PBS-gelatin $0.01 \%$-BSA $0.4 \%$ was added and incubated for $1 \mathrm{~h}$ at $37^{\circ} \mathrm{C}$. Streptavidin$\beta$-galactosidase ( 1 in 2500; Sigma) was added and incubated for $60 \mathrm{~min}$ at $37^{\circ} \mathrm{C}$. The reaction was developed with $50 \mu \mathrm{l}$ of ONPG (Sigma) for $60 \mathrm{~min}$ at $37^{\circ} \mathrm{C}$. Optical density (OD) was determined at $415 \mathrm{~nm}$ in an ELISA reader (BioRad, Hercules, CA, USA). The same steps were followed for IgG subclasses and $\operatorname{IgA}$ determinations. The respective MAbs - anti-human $\gamma$ chains, $\gamma 1, \gamma 2, \gamma 3, \gamma 4$ (Sigma) - were used as recommended at dilutions of 1 in 600,1 in 1000,1 in 3000 and 1 in 2500, respectively. Preliminary titration assays with four positive control sera with different titres of anti-P. brasiliensis antibodies (2048, 512, 64 and 4 in the CIE test) were performed to determine the optimal dilutions of the patients' sera. The following working dilutions were then used in this study: 1 in 5000 for total $\mathrm{IgG}, 1$ in 200 for $\operatorname{IgG} 1,1$ in 600 for $\operatorname{IgG} 2,1$ in 100 for IgG3, 1 in 25 for IgG4 and 1 in 100 for IgA. These results were further confirmed by dilution experiments with patients' sera (data not shown). Cut-off values were calculated from the mean +3 SD of sera from 40 healthy donors. The assays with the patients' sera incorporated positive and negative control sera.

\section{SDS-PAGE and immunoblotting procedure}

Electrophoresis in polyacrylamide $10 \%$ gels with a stacking gel of $5 \%$ were run with a buffer system as described by Laemmli [11]. The somatic antigen was solubilised in buffer containing $62.5 \mathrm{mM}$ Tris- $\mathrm{HCl}(\mathrm{pH}$ 6.8 ), SDS $2 \%$, glycerol $20 \%$ and $0.5 \mathrm{M}$ DL-dithiothreitol and then heated at $100^{\circ} \mathrm{C}$ for $2 \mathrm{~min}$. For each sample, c. $20 \mu \mathrm{g}$ were applied to the gel. Gels were stained with silver and molecular mass was determined by the use of a $20-94-\mathrm{kDa}$ standard kit (Pharmacia, Uppsala, Sweden). After separation of the somatic antigen in SDS-PAGE, blots were prepared as described by Towbin et al. [12]. Nitrocellulose paper (BioRad, Hercules, CA, USA) was hydrated in transfer buffer (methanol 20\%, $25 \mathrm{mM}$ Tris base, $192 \mathrm{~mm}$ glycine) at $\mathrm{pH} 8.3$, then aligned with the gel and placed in an electroblot apparatus ( $25 \mathrm{~V}$, overnight). After transfer, the paper was cut into strips and incubated with a solution of skim milk 5\% in PBS (SM-PBS) at room temperature for $2 \mathrm{~h}$. Strips were then incubated with sera diluted 1 in 20 in SM-PBS for $18 \mathrm{~h}$ at room temperature. After washing in PBS, the strips were 
incubated with mouse anti-human heavy chain-specific $\operatorname{IgG} 1, \operatorname{IgG} 2, \operatorname{IgG} 4$ and $\operatorname{IgA}$ conjugate (Sigma) at room temperature. Strips were washed and bands were visualised with diaminobenzidine $-\mathrm{H}_{2} \mathrm{O}_{2}$ substrate.

\section{Statistical analysis}

Values obtained for juvenile and adult patients were compared by the Mann-Whitney test. Differences were considered significant at $\mathrm{p}<0.05$. The Spearman test was used in the correlation studies.
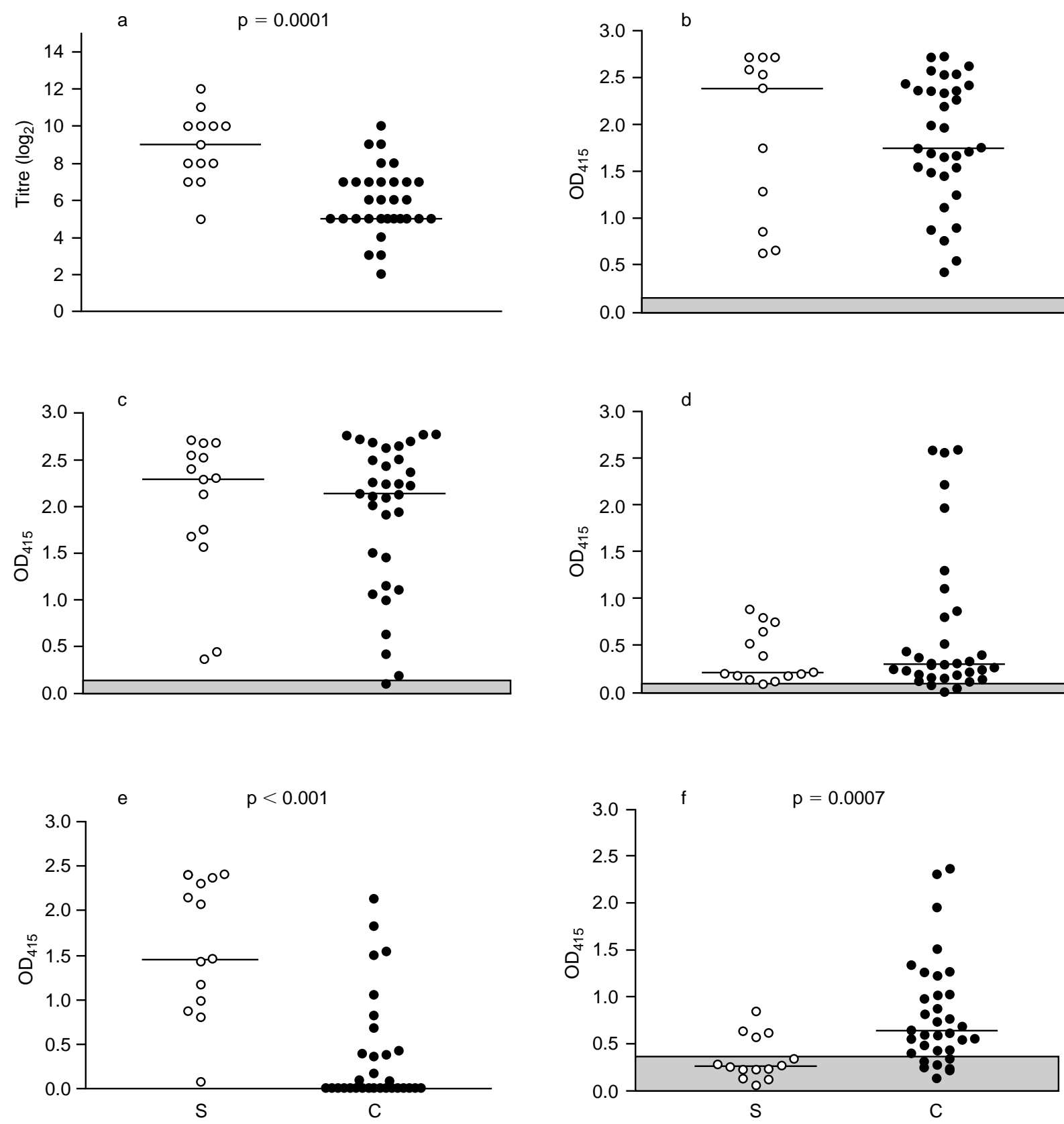

Fig. 1. Results of anti-P. brasiliensis culture filtrate antibody titres measured by CIE (a) and $\operatorname{IgG}(\mathbf{b}), \operatorname{IgG} 1$ (c), IgG2 (d), IgG4 (e), and IgA (f) antibody reactivity to P. brasiliensis somatic antigen, measured by ELISA, in the sera of SAF $(\mathrm{S} ; \circ)$ and CF $(\mathrm{C} ; \bullet)$ paracoccidioidomycosis patients. Each dot represents the value from a single patient and the horizontal lines represent the median value from the group. The shaded area corresponds to the mean $+3 \mathrm{SD}$ of the results from 40 healthy donors' sera. The statistical significance level, when present, is indicated for each comparison between SAF and CF patients. 
higher amounts of specific antibodies than patients with the $\mathrm{CF}$, as detected by CIE. IgG antibodies were also detected in all patients by ELISA, with slightly higher levels in SAF patients than in $\mathrm{CF}$ patients $\left(\mathrm{OD}_{415}\right.$ medians 2.4 and 1.7, respectively); however, these results did not reach statistical significance. IgG1 subclass antibodies were detected above the cut-off level in all SAF patients and in $94 \%$ of the CF patients; a high reactivity $\left(\mathrm{OD}_{415}>1.0\right)$ was generally detected within this subclass in both groups (SAF, 86\%; CF, $85 \%$ ). For the IgG2 subclass antibodies, although the reactivity was above the cut-off level in the majority of the patients $(93 \%$ in SAF patients and $94 \%$ in $\mathrm{CF}$ patients), a few patients, with the CF only $(\mathrm{n}=7$, $21 \%$ ), had $\mathrm{OD}_{415}$ values $>1.0$. IgG3 antibodies were either not detected above the cut-off point or were detected at low levels (data not shown). Conversely, IgG4 antibodies were found in all SAF patients, usually with high reactivity, but were not detectable in a majority (58\%) of the CF patients. The median $\mathrm{OD}_{415}$ was significantly higher in the former than in the latter (1.4 versus $0.0, \mathrm{p}<0.0001$ ). Reactivity for IgA was found above the cut-off level mainly in the CF group $(73 \%)$, but only in a minority of patients $(29 \%)$ in the SAF group. Their median $\mathrm{OD}_{415}$ were significantly different: (0.64 versus $0.26, \mathrm{p}=0.007)$.

Determination of antibody titres by CIE has been used routinely by our group as a good correlate of disease severity. Hence, this raised the question as to whether the results obtained by ELISA would correlate with those obtained by CIE. Of all the subclass determinations, only IgG4 and IgA (the latter in CF patients only) gave a correlation between the two methodologies ( $\mathrm{n}=46, \rho=0.49, \mathrm{p}<0.001$ and $\mathrm{n}=33, \rho=$ $0.44, \mathrm{p}=0.01$, respectively). The presence of any correlation between the ELISA results for IgG and its subclasses was also investigated. Correlation was found for IgG1 ( $\mathrm{n}=44, \rho=0.76, \mathrm{p}<0.001), \operatorname{IgG} 2(\mathrm{n}=44$, $\rho=0.45, \mathrm{p}=0.002$ ) and IgG4 (particularly in the SAF group, $\mathrm{n}=11, \rho=0.92, \mathrm{p}<0.001)$. Finally, a correlation was observed in $\mathrm{CF}$ patients between $\mathrm{IgG}$ and $\operatorname{IgA}(\rho=0.62, \mathrm{p}<0.001)$ and, to a lesser extent, between IgG and IgG2 ( $\rho=0.46, \mathrm{p}=0.007)$.

The study then evaluated the pattern of recognition of the IgG1, IgG2, IgG4 and IgA antibodies directed to the P. brasiliensis somatic antigen by Western blotting. As shown in Fig. 2a, IgG1 from both patient groups recognised several antigen fractions, including one of $43 \mathrm{kDa}$ that corresponds to the main $P$. brasiliensis antigen used for diagnosis (data not shown). It can also be seen that low mol. wt fractions were preferentially recognised by sera from the sub-acute group, except for a $27-\mathrm{kDa}$ fraction that was also recognised by serum samples from two CF patients. The 43-kDa fraction was recognised by $\operatorname{IgG} 2$ antibodies together with higher mol. wt fractions $(>94 \mathrm{kDa})$, especially in the $\mathrm{CF}$ patients with high IgG2 reactivity in the ELISA (Fig. $2 b$ ). The pattern of recognition by IgG4 antibodies was heterogeneous even in sera from the SAF patients, which had a strong IgG4 reactivity in the ELISA (Fig. 2c). Finally, IgA-rich sera from $\mathrm{CF}$ patients recognised not only the immunodominant $43-\mathrm{kDa}$ fraction (four of eight sera), but several other fractions of variable molecular size (Fig. 2d). The serum samples tested from SAF patients showed a weak reactivity in agreement with the low ELISA reactivity.

\section{Discussion}

Higher antibody reactivity against the crude filtrate antigen by $\mathrm{CIE}$ in SAF than $\mathrm{CF}$ form patients was observed in the present study, which is in agreement with the results of an earlier study [7] and with the notion that SAF disease is generally more severe [1]. In contrast, although SAF patients had slightly higher IgG reactivity against the somatic antigen by ELISA, there was no statistical difference between these and the CF patients. In an earlier study [8], CF patients showed lower antibody reactivity than SAF patients. In that study, the CF group comprised patients with multifocal and unifocal disease, whereas in the present study, unifocal patients were rare (only five patients). Patients with CF unifocal usually present with low anti- $P$. brasiliensis antibody titres, which explains the lower reactivity in the previous results. It is interesting to note that, although both the ELISA-IgG and CIE have already been proved useful to monitor severity of disease and treatment follow-up [8], no correlation was found between them in the present study. This could be due to differences in the sensitivity of the two methods or in the nature of the antigen, as the somatic antigen contains a higher number of fractions $[6,8]$.

The analysis of the isotype representation of the $\mathrm{IgG}$ reactivity indicated that the two forms of the disease have distinct profiles. The present study employed an antigenic preparation that was more representative of the whole fungus and extended earlier observations with the specific 43-kDa antigen [13]. In the present study, whereas a high level of IgG1 reactivity was detected in the majority of patients in both groups, IgG4 reactivity was mainly associated with the SAF group. A high level of $\mathrm{IgG} 2$ reactivity was only seen in some $\mathrm{CF}$ patients. Based on the knowledge that a conversion to IgG4 is dependent on interleukin (IL-4) $[14,15]$ and that a conversion to $\operatorname{IgG} 2$ is influenced by interferon(IFN) $-\gamma[15,16]$, it is suggested that the SAF of the disease is related to a Th2-type pattern of immune response. This pattern of humoral immune response would be associated with the more intensely depressed cellular immune function of this form of the disease. Conversely, in some patients with the CF, a Th1-type pattern of immune response would be expected, because sufficient IFN- $\gamma$ would have been produced to promote the conversion to $\mathrm{IgG} 2$ during the immune response. 
a
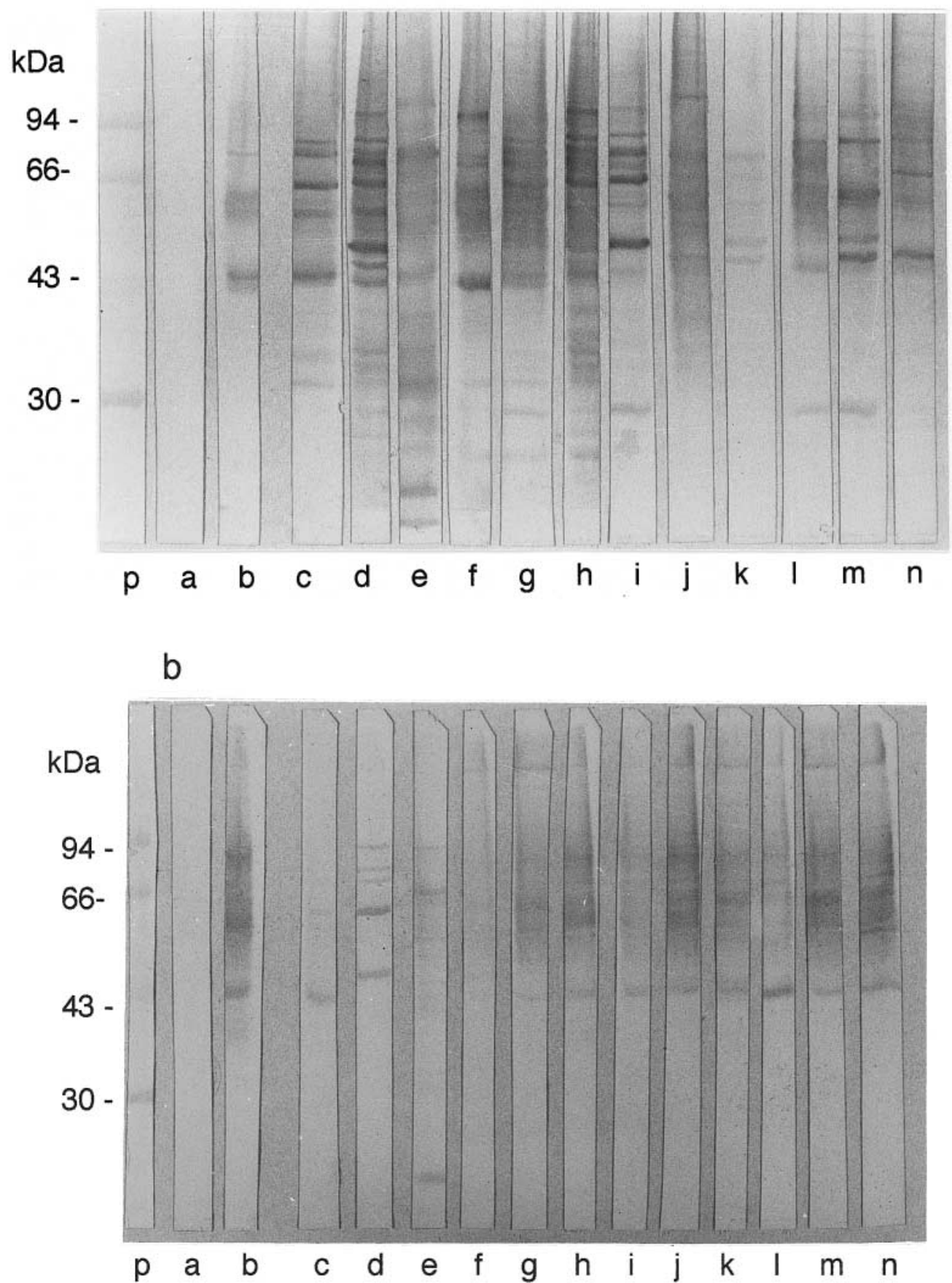

Fig. 2. Antibody isotype response, (a) IgG1, (b) IgG2, (c) IgG4 and (d) IgA, from SAF and CF PCM patients to the $P$. brasiliensis somatic antigen, as analysed by immunoblot; (a-d): lane p, mol. wt standards; a, negative control serum; $\mathbf{b}$, positive control serum. (a) Lanes $\mathbf{c}-\mathbf{h}$, SAF patients; i-n, CF patients. (b) Lanes $\mathbf{c}-\mathbf{e}$, SAF patients; f-n, CF patients. (c) Lanes $\mathbf{c}-\mathbf{j}$, SAF patients; $\mathbf{k}-\mathbf{n}$, CF patients. (d) Lanes $\mathbf{c}-\mathbf{f}$, SAF patients; $\mathbf{g}-\mathbf{n}$, CF patients.

Thus, in addition to the suggestion that it might be a marker of acute disease, IgG4 may also be a marker of disease severity and a good parameter for treatment follow-up, as it correlated well with CIE. IgA reactivity, on the other hand, was consistently seen only in the CF patients. This finding is not surprising because mucosal involvement of the respiratory tract, from lungs to the oral mucosa, is a main feature of this form and rare in the SAF [1]. Chronic antigen inflammation of mucosa is well known as a potent stimulus for the secretion of IgA antibodies [17]. In fact, IgA reactivity correlated well with CIE in the CF patients and may also eventually serve as an additional parameter for monitoring treatment response. Studies are currently in progress to test this hypothesis.

An alternative factor that could also have contributed to the different results in SAF and CF is age. SAF patients were 5-28 years old, whereas CF patients were 35-72 years old. Indeed, significant changes in serum 
C
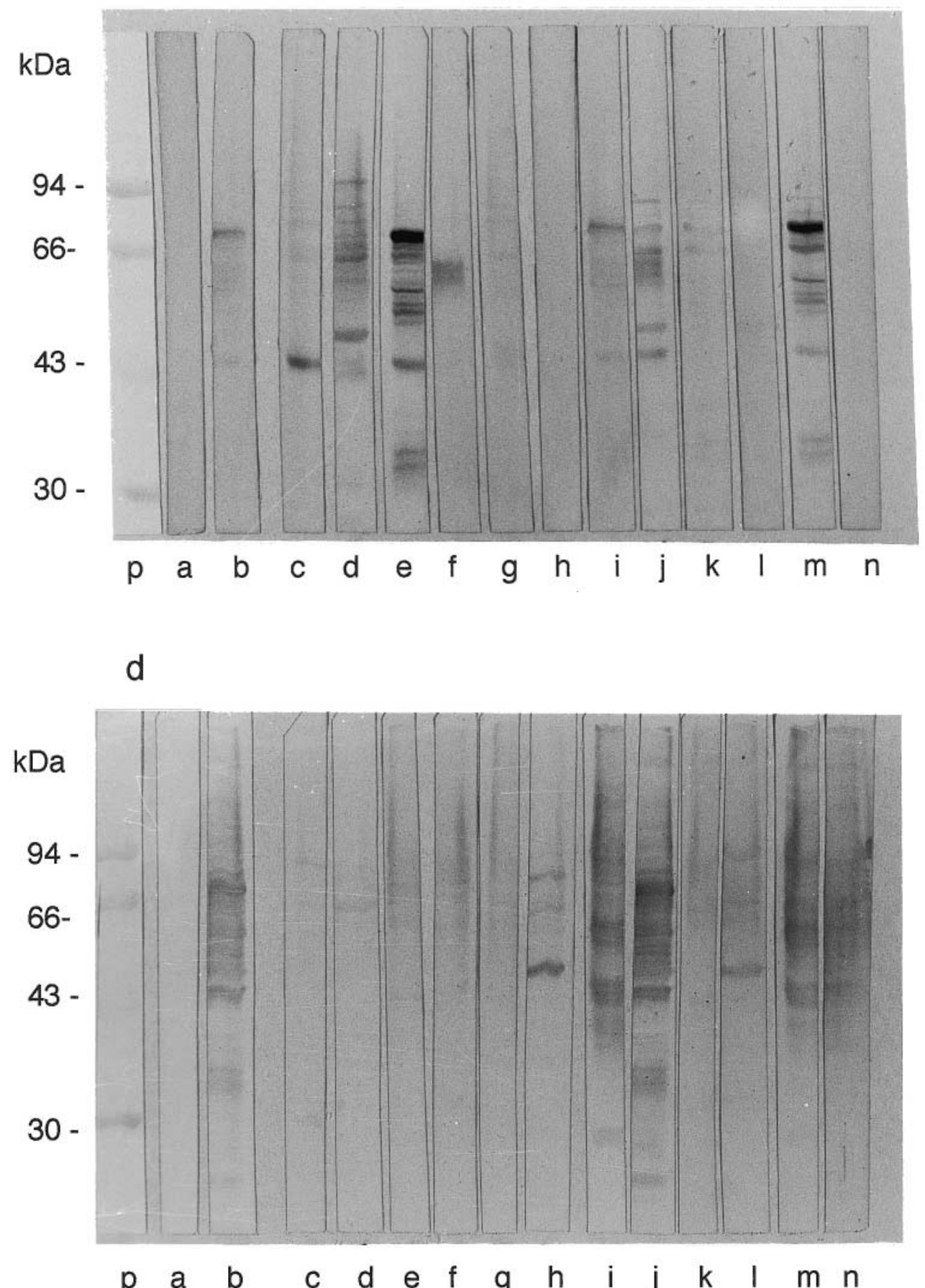

Fig. 2. (continued)

immunoglobulin levels are found with ageing [18]. It has been shown that the serum levels of the $\operatorname{IgA}, \operatorname{IgG} 1$, $\mathrm{IgG} 2$ and $\mathrm{IgG} 3$ isotypes, but not IgG4, increased in older individuals [19]. In contrast, the ability to respond to a specific antigen challenge with specific antibody production decreases with age [18]. Thus, it seems unlikely that age has, by itself, determined the differences in the two clinical groups. In human strongyloidiasis, for example, chronicity of infection did not correlate with specific IgA and IgG4 antibody levels, and IgG1 antibody levels were higher in younger patients [20]. The high levels of IgG4 were probably the result of repeated antigen exposure through auto-infection, most commonly seen in the young. A similar hypothesis was also sustained for the high IgG4 levels in younger schistosomiasis patients $[21,22]$. Therefore, more than a chronic antigen stimulus, these situations would represent a challenge with heavy antigen loads. This argument may also apply to SAF patients, in whom a heavier fungal load, compared with CF patients, is expected [1]. Moreover, the IgG4 subclass, by neither fixing complement nor having opsonising activity [23], could favour the successful establishment of a higher number of 
parasites in the host and the progressive fungal dissemination.

Interestingly, the levels of IgG3 reactivity were very low or absent, as has already been seen with the $P$. brasiliensis-specific fraction of $43 \mathrm{kDa}$ [13]. In other infectious conditions, in which the antibody profile is also predominantly influenced by a Th2 pattern of immune response and characterised by high levels of specific IgG4 or IgE antibodies, or both, there were low levels of the IgG3 subclass [24-26].

Up to now, the $43-\mathrm{kDa}$ molecule has been considered the main diagnostic antigen in PCM and a possible inducer of protective immune response [27, 28]. However, several other glycoproteins, of $22-25 \mathrm{kDa}$ [29], $27 \mathrm{kDa}$ [30], $58 \mathrm{kDa}$ [31], $70 \mathrm{kDa}$ [32] and $87 \mathrm{kDa}$ [33], have been described recently as being widely recognised by PCM patients' sera. Therefore, these antigens and probably others may all be relevant to the host immune response, as well as to the immunopathogenesis and diagnosis of the mycosis. This study then addressed the question as to whether different fractions of the somatic antigen were recognised in a specific manner by the subclasses of IgG or by IgA. Although a limited number of sera from each clinical presentation could be analysed by immunoblotting, the results indicate that the pattern of antigen fractions recognised by each presentation was dissimilar. This was more evident for $\mathrm{IgG1}$, in which a number of low mol. wt fractions, including the $27-\mathrm{kDa}$ fraction, were predominantly recognised by SAF sera, and for IgA, by which low mol. wt fractions were recognised by the CF sera. Even though the $43-\mathrm{kDa}$ fraction remained the most frequently recognised fraction by all subclasses and by $\operatorname{IgA}$, these results emphasise that other less well characterised fractions may be important and merit further investigation.

This work was supported by the Fundação de Amparo à Pesquisa do Estado de São Paulo \#96/1129-0 and \#96/5789-4, Conselho Nacional de Desenvolvimento Científico e Tecnológico \#301487/96-0 and Laboratórios de Investigação Médica do Hospital das Clínicas da FMUSP.

\section{References}

1. Franco MF, Mendes RP, Moscardi-Bacchi M, Rezkallah-Iwasso M, Montenegro MR. Paracoccidioidomycosis. Baillières Clin Trop Med Comum Dis 1989; 4: 185-220.

2. Restrepo-Moreno A. Ecology of Paracoccidioides brasiliensis. In: Franco M, da Silva Lacaz C, Restrepo-Moreno A, Del Negro G (eds) Paracoccidioidomycosis. Boca Raton, FL, CRC Press. 1994: 121-130.

3. Chequer-Bou-Habib D, Daniel-Ribeiro C, Banic DM, do Valle ACF, Galvão-Castro B. Polyclonal B cell activation in paracoccidioidomycosis. Mycopathologia 1989; 108: 89-93.

4. Benard G, Durandy A, Assis CM et al. Responses of T and B lymphocytes to a Paracoccidioides brasiliensis cell wall extract in healthy sensitized and non-sensitized subjects. Am J Trop Med Hyg 1995; 53: 189-194.

5. Benard G, Hong MA, Del Negro GMB, Batista L, ShikanaiYasuda MA, Duarte AJS. Antigen-specific immunosuppression in paracoccidioidomycosis. Am J Trop Med Hyg 1996; 54: $7-12$
6. Mendes-Giannini MJS, Del Negro GMB, Siqueria AM. Serodiagnosis. In: Franco M, da Silva Lacaz C, RestrepoMoreno A, Del Negro G (eds) Paracoccidioidomycosis. Boca Raton, FL, CRC Press. 1994: 345-363.

7. Del Negro GMB, Garcia NM, Rodrigues EG et al. The sensitivity, specificity and efficiency values of some serological tests used in the diagnosis of paracoccidioidomycosis. Rev Inst Med Trop Sao Paulo 1991; 33: 227-280.

8. Del Negro GMB, Pereira CN, Andrade HF et al. Evaluation of tests for antibody response in the follow-up of patients with acute and chronic forms of paracoccidioidomycosis. $J$ Med Microbiol 2000; 49: 37-46.

9. Lowry $\mathrm{OH}$, Rosenbrough $\mathrm{NJ}$, Farr AL, Randall RJ. Protein measurement with the folin phenol reagent. J Biol Chem 1951; 193: $265-275$.

10. Mendes Giannini MJS, Bueno JP, Shikanai-Yasuda MA, Ferreira AW, Masuda A. Antibody response to the $43 \mathrm{kDa}$ glycoprotein of Paracoccidioides brasiliensis as a marker for the evaluation of patients under treatment. Am J Trop Med Hyg 1990; 43: 200-206.

11. Laemmli UK. Cleavage of structural proteins during the assembly of the head of bacteriophage T4. Nature 1970; 227: $680-685$.

12. Towbin H, Staehelin T, Gordon J. Electrophoretic transfer of proteins from polyacrylamide gels to nitrocellulose sheets: procedure and some applications. Proc Natl Acad Sci USA 1979; 76: 4350-4354

13. Baida H, Biselli PJC, Juvenale M et al. Differential antibody isotype expression to the major Paracoccidioides brasiliensis antigen in juvenile and adult form paracoccidioidomycosis. Microbes and Infection 1999; 1: 273-278.

14. Fujieda S, Zhang K, Saxon A. IL-4 plus CD40 monoclonal antibody induces human B cells $\gamma$ subclass-specific isotype switch: switching to $\gamma 1, \gamma 3$, and $\gamma 4$, but not $\gamma 2$. J Immunol 1995; 155: 2318-2328.

15. Kitani A, Strober W. Regulation of $\mathrm{C} \gamma$ subclass germ-line transcripts in human peripheral blood B cells. J Immunol 1993; 151: $3478-3488$.

16. Kawano Y, Noma T. Role of interleukin-2 and interferon- $\gamma$ in inducing production of IgG subclasses in lymphocytes of human newborns. Immunology 1996; 88: 40-48.

17. Fayette J, Dubois B, Vandenabeele $\mathrm{S}$ et al. Human dentritic cells skew isotype switching of CD40-activated naive B cells towards $\operatorname{IgA}_{1}$ and $\operatorname{IgA}_{2}$. J Exp Med 1997; 185: 1909-1918.

18. Burns EA, Goodwin JS. Immunodeficiency of aging. Drugs Aging 1997; 11: 374-397.

19. Paganelli R, Quinti I, Fagiolo U et al. Changes in circulating $\mathrm{B}$ cells and immunoglobulin classes and subclasses in a healthy aged population. Clin Exp Immunol 1992; 90: $351-354$.

20. Atkins NS, Lindo JF, Lee MG et al. Humoral responses in human strongyloidiasis: correlations with infection chronicity. Trans R Soc Trop Med Hyg 1997; 91: 609-613.

21. Hagan P, Blumenthal UJ, Dunne D, Simpson AJG, Wilkins HA. Human IgE, IgG4 and resistance to reinfection with Schistosoma haematobium. Nature 1991; 349: 243-245.

22. Demeure CE, Rihet P, Abel L, Ouattara M, Burgois A, Dessein AJ. Resistance to Schistosoma mansoni in humans: influence of the $\mathrm{IgE} / \mathrm{IgG} 4$ balance and $\mathrm{IgG} 2$ in immunity to reinfection after chemotherapy. J Infect Dis 1993; 168: 1000-1008.

23. Hamilton RG. Human IgG subclass measurements in the clinical laboratory. Clin Chem 1987; 33: 1707-1725.

24. Kwan-Lim G-E, Forsyth KP, Maizels RM. Filarial-specific IgG4 response correlates with active Wuchereria bancrofti infection. J Immunol 1990; 145: 4298-4305.

25. Kurniawan A, Yazdanbakhsh M, van Ree R et al. Differential expression of $\mathrm{IgE}$ and IgG4 specific antibody responses in asymptomatic and chronic human filariasis. J Immunol 1993; 150: $3941-3950$.

26. Tomee JFC, Dubois AEJ, Köeter GH, Beaumont F, van der Werf TS, Kauffman HF. Specific IgG4 responses during chronic and transient antigen exposure in aspergillosis. $\mathrm{Am} \mathrm{J}$ Resp Crit Care Med 1996; 153: 1952-1957.

27. Travassos LR, Puccia R, Cisalpino $\mathrm{P}$ et al. Biochemistry and molecular biology of the main diagnostic antigen of Paracoccidioides brasiliensis. Arch Med Res 1995; 26: 297-304.

28. Taborda CP, Juliano MA, Puccia R, Franco M, Travassos LR. Mapping of the T-cell epitope in the major 43-kilodalton glycoprotein of Paracoccidioides brasiliensis which induces a 
Th-1 response protective against fungal infection in $\mathrm{BALB} / \mathrm{c}$ mice. Infect Immun 1998; 66: 786-793.

29. Figueroa JI, Hamilton A, Allen M, Hay R. Immunohistochemical detection of a novel 22- to 25-Kilodalton glycoprotein of Paracoccidioides brasiliensis in biopsy material and partial characterization by using species-specific monoclonal antibodies. J Clin Microbiol 1994; 32: 1566-1574.

30. McEwen JG, Ortiz BL, Garcia AM, Florez AM, Botero S, Restrepo A. Molecular cloning, nucleotide sequencing, and characterization of a $27-\mathrm{kDa}$ antigenic protein from Paracoccidioides brasiliensis. Fungal Genet Biol 1996; 20: $125-131$.
31. Figueroa JI, Hamilton AJ, Allen MH, Hay RJ. Isolation and partial characterization of a Paracoccidioides brasiliensis 58 $\mathrm{kDa}$ extracellular glycoprotein which is recognized by human immune sera. Trans $R$ Soc Trop Med Hyg 1995; 89: 566572.

32. Camargo ZP, Unterkircher C, Travassos LR. Identification of antigenic polypeptides of Paracoccidioides brasiliensis by immunoblotting. J Med Vet Mycol 1989; 27: 407-412.

33. Gómez BL, Figueroa JI, Hamilton AJ et al. Use of monoclonal antibodies in diagnosis of paracoccidioidomycosis: new strategies for detection of circulating antigens. J Clin Microbiol 1997; 35: 3278-3283. 